\title{
NOVO ESCOPO E NOVA EQUIPE EDITORIAL DA REVISTA S\&G
}

Estefan Monteiro da Fonseca oceano25@hotmail.com Universidade Federal Fluminense UFF, Niterói, Rio de Janeiro, Brasil.

\section{Marcelo de Almeida \\ Pompermeyer}

marcelo@valorainova.com.br Universidade Federal Fluminense UFF, Niterói, Rio de Janeiro, Brasil.

\section{Sidney Luiz de Matos Mello}

smello@id.uff.br

Universidade Federal Fluminense UFF, Niterói, Rio de Janeiro, Brasil.

\section{lasmim Esteves Lattanzi} iasmimlattanzi@id.uff.br Universidade Federal Fluminense UFF, Niterói, Rio de Janeiro, Brasil.
Ao longo de sua evolução, o ser humano passou de um organismo habitante para um ator modificador do meio ambiente, sendo marcada sua existência no planeta Terra através do conceito de Antropoceno. Sua adaptação às dificuldades impostas pelos ecossistemas naturais Ihe obrigou a criar tecnologias que permitissem sua perpetuação. Inicialmente, considerava-se a ideia de recursos infinitos e resiliência ilimitada do meio ambiente. Hoje, porém, em virtude do desenvolvimento de novas tecnologias e calibração de novos métodos de pesquisa, passa a ser um senso comum, no meio científico, que a simples presença do ser humano, seu consumo e os resíduos gerados por ele estão modificando de forma irreversível o ambiente no qual habitamos. Exemplo claro da evolução dos impactos no planeta Terra é o surgimento de novas temáticas, como a difusão do lixo pelos oceanos, o descobrimento de novos poluentes como desreguladores endócrinos e microplásticos e como estes afetam os diversos elos da rede trófica, além da disseminação crescente de novas endemias por todo o globo.

Dentro deste contexto, a revista eletrônica "SISTEMAS E GESTÃO (S\&G)" passa por um processo de reformulação decorrente da crescente demanda de dados que possam munir o meio de pesquisa de informações que ajudem a entender a transição que o planeta Terra está passando. Paralelamente, não abandonando questões relativas a métodos de gestão nas diversas áreas tradicionalmente abordadas pela revista, esta reforça o foco nas medidas de governabilidade, de forma a estimular o caráter prático das informações publicadas. Assim sendo, pretende-se diminuir o distanciamento entre a ciência produzida pelo meio acadêmico e sua aplicabilidade no desenvolvimento de soluções inovadoras que contribuam para a convivência mais equilibrada entre o ser humano e o meio ambiente. Seguindo essa nova perspectiva, o presente periódico passa a adotar formalmente a abreviatura S\&G JOURNAL com o intuito de estimular o processo de internacionalização e projeção da revista.

Convidamos a toda a comunidade científica global a contribuir com informações relevantes nos diversos temas que digam respeito ao ambiente natural, sustentabilidade e medidas positivas que possam ser propagadas em outras regiões.

Recebido: 05 fev. 2020

Aprovado: 08 fev. 2020

DOI: 10.20985/1980-5160.2020.v15n1.1616

Como citar: Fonseca, E.M., Pompermeyer, M.A., Mello, S.L.M., Lattanzi, I.E. (2020), Novo escopo e nova equipe editorial da Revista S\&G, Revista S\&G 15, No. 1, 1. https://revistasg.emnuvens.com.br/sg/article/view/1616 